\title{
On being attractive, social and visually appealing in social media: the effects of anthropomorphic tourism brands on Facebook fan pages
}

Article

Accepted Version

Creative Commons: Attribution-Noncommercial-No Derivative Works 4.0

Perez-Vega, R., Taheri, B., Farrington, T. and O'Gorman, K. (2018) On being attractive, social and visually appealing in social media: the effects of anthropomorphic tourism brands on Facebook fan pages. Tourism Management, 66. pp. 339347. ISSN 1879-3193 doi:

https://doi.org/10.1016/j.tourman.2017.11.013 Available at https://centaur.reading.ac.uk/67498/

It is advisable to refer to the publisher's version if you intend to cite from the work. See Guidance on citing.

To link to this article DOI: http://dx.doi.org/10.1016/j.tourman.2017.11.013

Publisher: Elsevier

All outputs in CentAUR are protected by Intellectual Property Rights law, including copyright law. Copyright and IPR is retained by the creators or other copyright holders. Terms and conditions for use of this material are defined in the End User Agreement. 


\section{www.reading.ac.uk/centaur}

\section{CentAUR}

Central Archive at the University of Reading

Reading's research outputs online 


\title{
On being attractive, social and visually appealing in social media: The effects of anthropomorphic tourism brands on Facebook fan pages
}

\author{
Rodrigo Perez-Vega ${ }^{a}$, Babak Taherib ${ }^{b}$, Thomas Farrington ${ }^{b}$ and Kevin $O^{\prime}$ Gorman $^{b}$ \\ ${ }^{a}$ Henley Business School, The University of Reading, Reading, UK \\ ${ }^{b}$ School of Social Sciences, Heriot-Watt University, Edinburgh, UK
}

\begin{abstract}
Social media platforms and their associated user-generated content are of increasing significance to the perception of tourism brands amongst consumers. Online fan pages offer a unique opportunity for tourism managers to effect positive engagements between their brand and consumer base. By viewing these online environments in relation to Social Response Theory, this study discerns the impact of brand fan pages with human-like attributes, suggesting that anthropomorphic cues positively influence user engagement. Using PLS-SEM analysis, the study empirically tests a theoretically developed higher-order construct of these anthropomorphic Fan Page Cues, composed of three first-order factors: social interactive value, visual appearance and identity attractiveness. Findings indicate that a social media platform with human-like characteristics positively engages consumers, the theoretical and practical implications of which are clearly presented.
\end{abstract}

\section{Keywords}

Social interactive value, visual appearance, identity attractiveness, fan page engagement, social response theory 


\section{Introduction and background}

Communication through social media is becoming increasingly sophisticated within the tourism industry, with an accompanied growth in research towards increasing online brand engagement behaviours (Hays, Page, \& Buhalis, 2013; Zeng \& Gerritsen, 2014; Leung, Bai, \& Stahura, 2015). Poor financial outcomes of social media use within tourism businesses (Chan \& Guillet, 2011) have led to increased research into the antecedents of user engagement, such as involvement (Hollebeek et al., 2014; Harrigan et al., 2017); community characteristics (Chan et al., 2014); and level of satisfaction (Van Doorn et al., 2010). Yet little attention has been given to the nature of the engagement object, the fan page itself, and how its perceived characteristics affect consumer behaviour. This study offers a new perspective on the nature of social media interactions, employing Social Response Theory (SRT) to suggest that consumers' online engagement may be enhanced through the use of certain anthropomorphic aesthetic and social cues, which we call Fan Page Cues (FPCs). The theoretical contribution of the paper is to identify three FPCs (social interactive value, visual appearance, and identity attractiveness), and trace their impacts upon experiential flow, fan page engagement, and behavioural intention. A higher-order construct of FPCs is developed and tested, comprised of three first-order factors: social interactive value, visual appearance and identity attractiveness (Lee, Hallak, \& Sardeshmukh, 2016). In examining the relationships between the use of social media sites, fan page engagement, and financial outcomes for tourism and hospitality organisations, we attend to the research question: can tourism fan page perceived characteristics, in the form of FPCs, improve the engagement and behavioural intentions outcomes of social media users?

\section{Literature Review}

This review introduces SRT and the constructs for FPCs (social interaction value, visual appearance and identity attractiveness), experiential flow, fan page engagement, and hedonic and utilitarian value.

\subsection{SRT}

SRT suggests that social cues arouse user responses to information technology with humanlike attributes (Moon, 2003). There is increasing evidence that people treat computers as social actors, and that computer-human interactions are also subject to behaviours found in human-human interactions (Moon, 2003). We argue that responses can also be extended to other types of online presence, such as social media websites, due to the tendency of human beings to anthropomorphise inanimate and abstract objects. Anthropomorphism is understood as the process of attributing mind, intentions, effortful thinking, emotional states, and behavioural features to non-human objects; a process through which consumers perceive brands as capable of reasoning and intent (Puzakova, Kwak, \& Rocereto, 2013).

SRT research shows the positive effects of social cues. Avatars are found to enhance customer satisfaction, attitudes towards products, behavioural intention and trust in online retailers (Wang \& Fodness, 2010). An avatar's perceived attractiveness increases the effectiveness of that virtual sales agent for products with low and moderate involvement (Jin \& Bolebruch, 2009). The positive effects of social cues facilitate purchase intentions and increase trust amongst older users. Research suggests that social media also elicits social response, providing interpersonal and highly communicative interaction among and between consumers and brand representatives. 
As SRT proposes that online environments be treated as anthropomorphised agents, we posit that Facebook fan pages can elicit social responses when exhibiting human-like attributes and social cues. Interactions between a user and fan page are thus affected by that page's visual appearance and identity attractiveness. Likewise, the social interaction value perceived by a fan page user will be critical in determining the page's social cues. We develop these three constructs to form FPCs. Wang et al. (2007) suggest an aggregated view of social response cues for e-commerce websites. The distinctiveness of social media websites lies in their priming elements of user engagement such as identity, relationships, and socialisation (Kietzmann, Hermkens, McCarthy, \& Silvestre, 2011). We propose that in the context of Facebook fan pages, three aggregated components form the cues relevant to eliciting a social response from users, in terms of fan page engagement and the state of experiential flow during page interaction: visual appearance, identity attractiveness and social interaction value. Fig.1 shows the conceptual model of online brand fan page engagement; SRT providing its overarching theory. The model integrates and explores relationships between FPCs, experiential flow (Wang \& Hsiao, 2012), fan page engagement (Verma, Jahn, \& Kunz, 2012), hedonic and utilitarian values (Overby \& Lee, 2006) and behavioural intentions (Chen \& Tsai, 2007; Baker \& Crompton, 2000; Fishbein \& Ajzen, 1975). FPCs is hypothesised as a higher-order molecular model embodied by three dimensions: visual appearance, identity attractiveness and social interaction value.

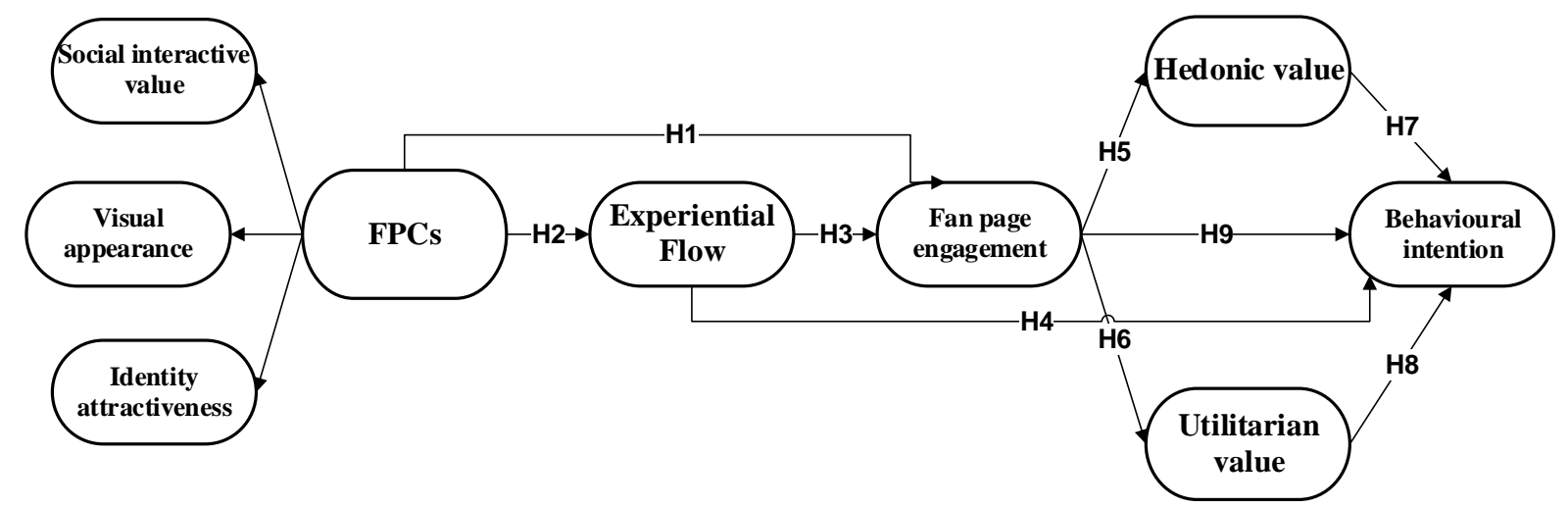

Fig 1. Conceptual model

\subsection{FPCS}

Visual appearance in an online context refers to website layout, images, look and feel (Shukla, 2014), indicating performance to customers and increasing satisfaction during online transactions (Schlosser, White \& Loyd, 2006). A well-designed website may increase consumer confidence and trust (Park \& Kim, 2003), thereby reducing perceptions of risk. Visual appearance is identified as a success factor for positive return on investment of websites (Park \& Gretzel, 2007). Therefore, we posit that visual appearance is an important determinant of a fan page's aesthetic cues.

Identity attractiveness is the degree to which individuals are attracted to, show preference for, and support relationships with a focal object (e.g. a brand), giving it enduring attributes. Consumers are likely to be attracted to brands that are similar to the consumer's identity; perceived as distinctive in traits valued by the consumer, or perceived as prestigious (Bhattacharya \& Sen, 2003). The degree of identity attractiveness of a brand is derived from identity communications such as advertising, branding efforts, and other customers (Bhattacharya \& Sen, 2003). Similar to human-tohuman interactions, elements of brand identity include a combination of the core values and demographics portrayed by the brand. Social media offers a means for interactions between users 
and brands, yet little is known concerning the effects of consumer identification through such channels. We posit that increased identity attractiveness in social media channels will intensify the aesthetic and social cues of the fan page. This is supported by research in human-to-human interactions, where the level of attractiveness modulates the intensity of the perceived physical and emotional traits of the attractive versus the unattractive subject (Main, DeBruine, Little, \& Jones, 2010).

Social interaction value is value perceived from the growth, maintenance and broadening of relationships with others (Jahn \& Kunz, 2012). Research finds this desire for social experience motivating shopping behaviour and the perceived value of the focal outlet (Kim, Kang, \& Kim, 2005). Social interaction may also motivate engagement in online environments, facilitating consumer interaction, yet is distinct from offline interaction, in allowing consumer interaction with the brand/merchant, making the interaction more engaging and enjoyable (Kim, 2002). In the context of tourism management, social interaction value is investigated under the construct of 'togetherness' or the value of 'social interaction for its own sake' and proposed as an intrinsic other-oriented active and reactive value (Komppula \& Gartner, 2013). We suggest that when users perceive social interaction value in a Facebook fan page, the social and aesthetic cues of the page increase, thus:

H1: FPCs are positively related to fan page engagement.

\subsection{Experiential flow}

Flow is the cognitive state whereby individuals become so involved in an activity that nothing else matters (Csikszentmihalyi, 2008). Novak, Hoffman and Duhachek (2003) distinguish between goal-oriented and experiential flow states. Research on the antecedents and consequences of flow in online environments has evolved from general website use (Novak, Hoffman, \& Yung, 2000) to specific online contexts, e.g. travel agencies (Gao \& Bai, 2014), tourism websites (Skadberg \& Kimmel, 2004), e-commerce sites (Wang, Baker, Wagner \& Wakefiled, 2007). Wang et al. (2007) find the positive impact on flow of online social cues (mediated by perceived levels of socialness). We posit a direct relationship between FPCs and experiential flow in social media websites (Oh \& Syn, 2015), enhanced by an environment typified by social interaction. This aligns with Csikszentmihalyi's (2008) view that being with others is an important aspect of experiential flow. Despite the importance of flow in the online user experience (Novak et al., 2000), its commercial value has been challenged (Zeithaml, Parasuraman, \& Malhotra, 2002). We examine the outcomes of experiential flow on fan page engagement and behavioural intention, adding to the body of research linking this construct to other commercial outcomes (Zhou, Li, \& Liu, 2010). We propose:

H2: FPCs are positively related to experiential flow.

H3: Experiential flow is positively related to fan page engagement.

H4: Experiential flow is positively related to behavioural intention.

\subsection{Hedonic and utilitarian value}

Interaction relationships occur when cost-benefit considerations exceed any alternative exchange (Park \& Kim, 2014). In the context of online brand communities (e.g. Facebook fan pages), 
members fulfil utilitarian needs such as the need for information, ideas and problem solutions. Thus, we suggest fan page engagement harnesses the utilitarian value of solving problems either by the brand or other community members. Experiential value involves affective and emotional elements that satisfy hedonic needs of sensory pleasure (Park \& Kim, 2014); elements found in the consumption experience. Within Facebook fan pages, hedonic value can be found in mentally and emotionally stimulating interactions between user, brand and other fan page community members (Nambisan \& Baron, 2009). We posit that some of the value users take from fan page engagement is purely experiential. Furthermore, there is evidence that utilitarian and hedonic value (as elements of the customer-perceived value equation of perceived benefits minus perceived costs) are critical factors affecting online purchase intentions (Lu \& Hsiao, 2010). Therefore, we propose that both hedonic and utilitarian value can lead to positive behavioural and purchase intentions towards the products/services interacted with during fan page engagement. We propose:

H5: Fan page engagement is positively related to hedonic value.

H6: Fan page engagement is positively related to utilitarian value.

H7: Hedonic value is positively related to behavioural intention.

H8: Utilitarian value is positively related to behavioural intention.

\subsection{Fan page engagement}

Engagement captures different forms of interactions (Hollebeek, et al., 2014), experiences (Calder et al., 2009; Brodie et al., 2011) and participation (Vivek et al., 2012; Wirtz et al., 2013) between the subject (customer/consumer) and the object (brands, communities, website). Jahn and Kunz $(2012$, p.349) define social media fan page engagement as "an integrative participation in the fan-page community," in the form of commenting, liking and sharing content within and beyond the fan-page community (Perez-Vega et al., 2016). Consumer engagement in offline settings (e.g. festivals) can lead to positive behavioural intentions (Organ et al., 2015; Sparks, 2007). Following Harrigan et al.'s (2017) assertion that engagement be treated as a process rather than an outcome (with evidence of engagement as an antecedent of loyalty), we posit a relationship between fan page engagement and behavioural intentions to purchase and use the brand. Thus:

H9: Fan page engagement is positively related to behavioural intention.

\section{Methods}

An online survey was created in Qualtrics. The pilot test led to minor revisions, and identified the need for a 'piped text' survey for clarity, showing the brand the participant mentioned at the beginning of the survey. A total of 630 usable responses were collected over three months in 2014. The majority of participants were in age category between 26 and 35 years old (31.3\%). 56.8\% were male.

Participants selected from a pool of online tourism brands that they remembered interacting with in the last 6 months, with the option to add a brand name if none listed met this criteria (see Appendix A for the survey sample). The conceptualisation of FPCs, as a composition of its parts, 
requires a higher-order operationalisation (Lee, Hallak \& Sardeshmukh, 2016; Wetzels, OdekerkenSchroder \& van Oppen, 2009). This continuous second-order measure includes 12 items that fall under three factors: social interactive value (Jahn \& Kunz, 2012), visual appearance (Shukla, 2014) and identity attractiveness (Marín \& Ruiz de Maya, 2013). The reflective measures include multiple-item scales for measuring experiential flow (Gao \& Bai, 2014), fan page engagement (Jahn \& Kunz, 2012), hedonic and utilitarian value (Wang, Baker, Wagner, \& Wakefield, 2007), and behavioural intentions (Gefen, Karahanna, \& Straub, 2003) (see Appendix A and B for the full list of items).

Common Method Variance (CMV) was assessed using Harman's single-factor. The findings of the factor analysis showed six factors (the highest portion of variance explained by one factor was 43\%). A common method factor was announced to the structured model via step-by-step partial least squares (PLS) (Liang et al., 2007). All loadings of the indicators to the common method factor were non-significant. The average variance of the indicators explained by the corresponding construct of interest was $62.7 \%$, while the average method-based variance was $1.1 \%$, yielding a ratio of $57: 1$. Therefore, it appeared CMV was not biasing results.

\section{Data analysis and results}

PLS structural equation modelling (PLS-SEM) is appropriate for the early stages of theory-building and non-normal distribution (Hair et al., 2017). Results show that items have skewness and kurtoses above the required cut-off point of -3 and +3 (Appendix B). PLS can be used in reflective, formative, and higher-order models (Hair, et al., 2017). Both the measurement and structural model were examined within SmartPLS 3.0; the non-parametric bootstrapping technique was tested with 630 samples (5000 subsamples).

\subsection{Analysis of reflective measurement model}

Composite reliability (CR), Cronbach's Alpha $(\alpha)$, factor loadings and average variance extracted (AVE) were employed to test reliability and validity. The factor loadings, CR and $\alpha$ indicated values above the mandatory thresholds of .7 (Hair, Black, Babin, \& Anderson, 2010). The AVE surpassed the threshold of .5 for all constructs (Hair et al., 2010) (see Table 1 and Appendix B). The Fornell and Larcker (1981) criterion was employed to test discriminant validity, which requires a construct's AVE to be larger than the square of its largest correlation with any construct (Table 2).

Table 1

Reliability, convergent validity and loadings of reflective and first-order measurement models.

\begin{tabular}{lllll}
\hline Construct & $\begin{array}{l}\text { Standard factor } \\
\text { loadings* }\end{array}$ & Cronbach's $\alpha$ & AVE & CR \\
\hline Fan Page engagement & $.877-.932$ & .940 & .820 & .958 \\
Experiential flow & $.847-.880$ & .829 & .745 & .897 \\
Hedonic value & $.707-.906$ & .928 & .688 & .929 \\
Identity attractiveness & $.874-.892$ & .856 & .777 & .913 \\
Behavioural intention & $.753-.830$ & .850 & .623 & .892 \\
Social interactive value & $.745-.835$ & .931 & .771 & .931 \\
Utilitarian value & $.727-.865$ & .915 & .644 & .916 \\
Visual appearance & $.728-.835$ & .841 & .616 & .889 \\
\hline
\end{tabular}

Notes: ${ }^{*} t>3.29$ at $p<.001$ 
Table 2

Correlation between constructs.

\begin{tabular}{llllllllll}
\hline & $(1)$ & $(2)$ & $(3)$ & $(4)$ & (5) & (6) & (7) & (8) & (9) \\
\hline (1) Fan Page Cues & 1 & & & & & & & & \\
(2) FPCs & .694 & 1 & & & & & & & \\
(3) Experiential flow & .533 & .517 & 1 & & & & & & \\
(4) Hedonic value & .524 & .385 & .389 & 1 & & & & & \\
(5) Identity attractiveness & .500 & .538 & .475 & .483 & 1 & & & & \\
(6) Behavioural intention & .503 & .565 & .437 & .541 & .494 & 1 & & & \\
(7) Social interactive value & .534 & .626 & .545 & .338 & .467 & .453 & 1 & & \\
(8) Utilitarian value & .515 & .725 & .556 & .460 & .594 & .576 & .531 & 1 & \\
(9) Visual appearance & .591 & .578 & .588 & .528 & .550 & .581 & .562 & .509 & 1 \\
Square root of AVEs & $\mathrm{n} / \mathrm{a}$ & .906 & .863 & .840 & .882 & .789 & .910 & .773 & .785 \\
\hline
\end{tabular}

\subsection{Analysis of the higher-order model}

$C R, \alpha$, and AVE values for first-order constructs are above the required threshold values (Table 1). Following Lee et al. (2016) and Wetzels et al. (2009) recommendation, we employed a repeated indicators approach in order to validate higher-order latent constructs in PLS-SEM. The relationship between the FPCs construct and its three first-order constructs is significant and the $R^{2}$ of each dimension is larger than recommended value of .5 (Fig. 2), which indicates FPCs construct explains more than $50 \%$ of the variance in its respective single-order constructs. Thus, the results confirm that FPCs is a second-order construct represented reflectively by three first-order dimensions.

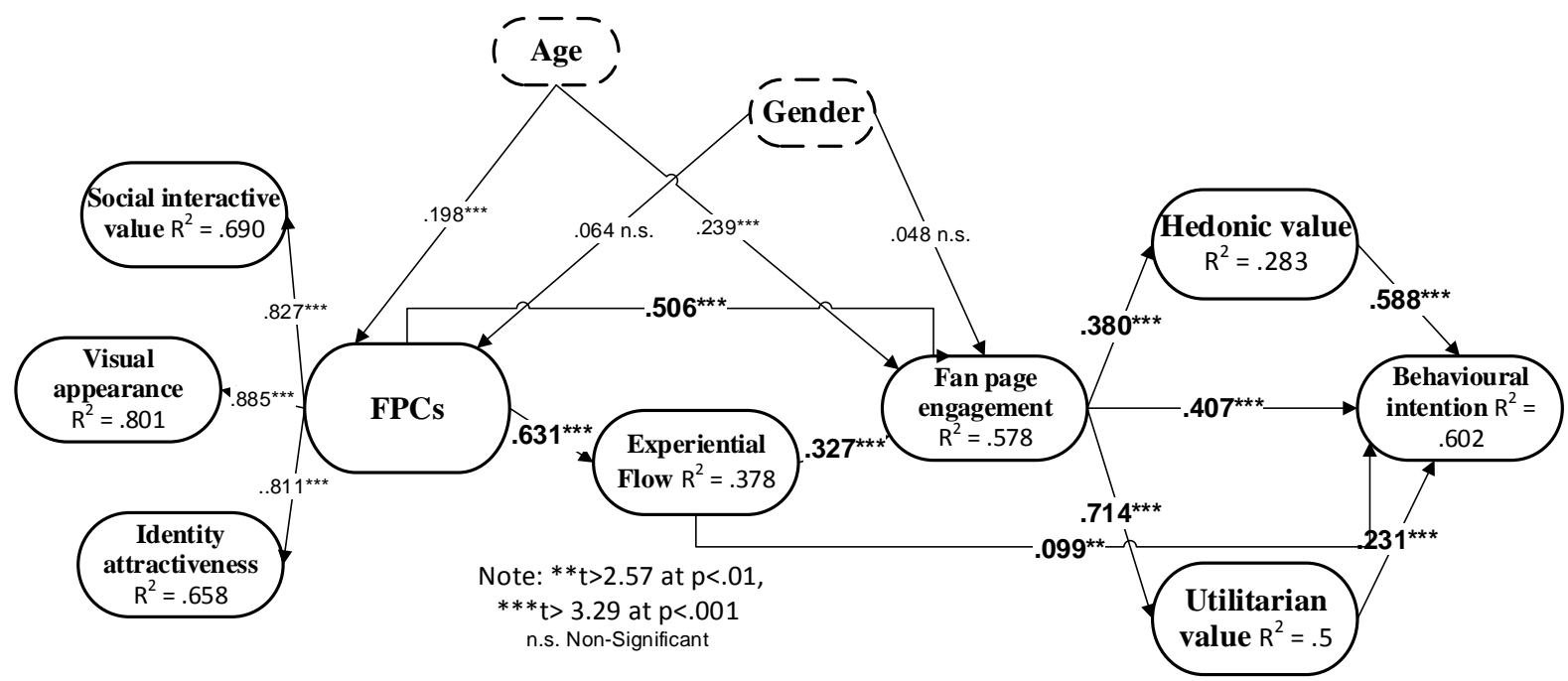

Fig 2. Results of PLS-SEM.

\subsection{Analysis of the structural model}

The results indicate that Cohen's effect size $f^{2}$ values are above .02 , which indicates satisfactory effects for the endogenous latent constructs (Henseler, Ringle, \& Sinkovics, 2009). The SRMR value for our model was 0.068 , which is less than the recommended value of 0.08 (Hair et al., 2017). Fig. 2 shows the results of assessing the direct effects. The findings indicate all eight 
hypotheses were supported and consistent with previous studies. In terms of gender, no effects were found on FPCs, supporting similar research (Wang et al., 2007).

\subsection{Post-hoc analysis of the indirect effects}

The findings suggest the potential existence of mediating relationships between several constructs. We followed Lee et al. (2016), calculating 95\% confidence interval (Cl). The findings indicate that FPCs indirectly influence fan page engagement through experiential flow (Cl: .130-.253). Since the direct impact was significant, the findings reveal that experiential flow partially mediates the influence of FPCs on Fan Page engagement. Experiential flow indirectly influences hedonic value through fan page engagement ( $\mathrm{Cl}:$.071-.142). Since the direct influence was significant, the findings reveal that fan page engagement partially mediates the influence of experiential flow on hedonic value. Experiential flow indirectly influences utilitarian value through fan page engagement (Cl: .149.258). Since the direct influence was significant, the findings reveal that fan page engagement partially mediates the influence of experiential flow on utilitarian value.

\section{Conclusions}

This study evaluated a structural model of FPCs, flow, fan page engagement, hedonic value, utilitarian value and purchase intention. The findings supported relationships hypothesised between all direct paths (Fig.2), supported by previous studies (Komppula \& Gartner, 2013; Lu \& Hsiao, 2010). Further testing for post-hoc analysis of indirect relationships revealed three indirect relationships. FPCS is confirmed as a higher-order construct, expanding on studies testing relationships between each of the three first-order constructs of FPCs and other constructs in our conceptual model.

Our theoretical contribution is threefold. First, the paper contributes to research into tourism management by addressing a theoretical gap regarding a brand's social media presence and its effects on consumer engagement. While a growing body of scholarship examines the antecedents and consequences of consumer engagement in tourism brands, there remains a lack of empirical research into the features of a brand's online presence that attract consumers, hold their attention, and increase the likelihood of their purchasing from or through that brand. By viewing online engagement through the lens of SRT, this paper contributes a theory of FPCs: consumers are positively engaged by an online presence that displays certain anthropomorphic features. A conceptual model is developed tracing the impact of FPCs upon the experience of flow, consumer engagement, and purchase intentions. Our study finds significant relationships amongst these constructs, from which we derive our theoretical implications. The evidence suggests that online pages deploying FPCs will more fully engage and produce positive purchase intentions in their users, leading to positive financial outcomes. Second, we extend the evidence that online settings can elicit social response from users, demonstrating that this behavioural response is not limited to regular and e-commerce websites (Wang et al., 2007), being also found in social media fan pages. We find that beyond explicit social cues, such as an avatar or voice, more abstract forms of social cues can also elicit a social response from Internet users.

The third contribution of this study is providing empirical evidence linking fan page engagement to behavioural intentions to purchase the brand's products and create value, thereby testing the relationship between branded online settings and positive commercial outcomes. This responds to the increased pressure placed upon tourism scholars and marketers to measure the 
positive impact of online activities on financial outcomes and return on investment (eMarketer, 2016), with further guidance on the online elements to be monitored to help explain overall social media performance. Furthermore, this study finds that gender had no effect on FPCs or fan page engagement, extending similar social media research (Pew Research Center, 2015) and supporting the argument that this applies to engagement and the perception of FPCs in social media settings. Age had a significant effect on both constructs, suggesting that practitioners should consider this variable as an indicator of the level of fan page engagement that they can expect to have in these settings. Brands targeted at younger customers may expect a more positive effect of FPCs on experiential flow and fan page engagement.

This study demonstrates that elements defining attractiveness in human-human interactions can also be found in interactions with digital brand representations, and should be considered when setting up and managing a brand presence online. Our findings shed light on the interplay between consumer fan page experience and tourism online brands, thus attending to contemporary discussions of online brand engagement, and determining the impacts and value of tourism fan page projects. A focus on these three FPCs factors in tourism marketing strategies may help to more effectively communicate marketing messages to consumers.

\subsection{Managerial implications}

Managers of tourism fan pages should continue to implement strategies aiming at increasing fan page engagement, which positively affects the perceived value of the brand and behavioural purchase intentions. Our research supports a focus on FPCs in the development of anthropomorphic characteristics of tourism social media pages as an additional strategy towards this goal. This research asserts the value of managing an online community around a fan page, highlighting the importance that consumers give to socialization in these settings, and the impact this has on levels of engagement and behavioural intention.

In practice, activities encouraging consumers to interact with other consumers in these channels can increase the perceived value of being part of the fan page community. The evidence also confirms the importance of visual elements in the fan page. Despite layout constraints, there is an increasing trend among social media sites to extend the ability of brands to create more visually appealing content (e.g. Facebook Canvas) and managers of tourism brands should embrace the use of tools that allow the brand to display a higher level of creativity and sophistication, thereby facilitating the anthropomorphisation of the brand in digital environments.

\subsection{Limitations and future directions}

This study focused on only one type of social media website (i.e. fan pages). Research into social media responses should expand to other types of social media with lower and higher levels of social presence, e.g. blogs, other content communities and virtual social worlds (Kaplan \& Haenlein, 2010). Social media websites represent an ideal environment to elicit social responses from Internet users, to enhance their value experience and achieve desired outcomes for brands. Another limitation is the focus on two desirable outcomes (e.g. fan page engagement and behavioural intention). There is scope to further test the effect of FPCs on other outcomes valuable to tourism brands. 


\section{References}

Baker, D.A., \& Crompton, J.L. (2000). Quality, satisfaction and behavioral intentions. Annals of Tourism Research, 27, 785-804.

Bhattacharya, C.B., \& Sen, S. (2003). Consumer-company identification: A framework for understanding consumers' relationships with companies. Journal of marketing, 67,76-88.

Chan, N.L., \& Guillet, B.D. (2011). Investigation of social media marketing: how does the hotel industry in Hong Kong perform in marketing on social media websites? Journal of Travel \& Tourism Marketing, 28, 345-368.

Chan, T. K. H., Zheng, X., Cheung, C. M. K., Lee, M. K. O., \& Lee, Z. W. Y. (2014). Antecedents and consequences of customer engagement in online brand communities. Journal of Marketing Analytics, 2(2), 81-97.

hen, C.F., \& Tsai, D.C. (2007). How destination image and evaluative factors affect behavioral intentions? Tourism Management, 28, 1115-1122.

Csikszentmihalyi, M. (2008). Flow: The Psychology of Optimal Experience. New York: Harper Perennial Modern Classics.

eMarketer (2016). Measuring ROI Still the Top Struggle for Social Marketers [Website] Available from: https://www.emarketer.com/Article/Measuring-ROI-Still-Top-Struggle-SocialMarketers/1014196\#sthash.9iU2aNkL.dpuf. Accessed 12-02-2017.

Fornell, C., \& Larcker, D.F. (1981). Evaluating structural equation models with unobservable variables and measurement error. Journal of Marketing Research, 18,39-50.

Gao, L., \& Bai, X. (2014). Online consumer behaviour and its relationship to website atmospheric induced flow: Insights into online travel agencies in China. Journal of Retailing and Consumer Services, 21,653-665.

Gefen, D., Karahanna, E., \& Straub, D.W. (2003). Trust and TAM in online shopping: an integrated model. Mis Quarterly, 27,51-90.

Hair, J.F.J., Black, W.C., Babin, B.J., \& Anderson, R.E. (2010). Multivariate Data Analysis: A Global Perspective (7th ed.). USA: Pearson.

Hair, J.F.J., Hult, G. T.M., Ringle, C.M., \& Sarstedt, M. (2017). A primer on Partial Least Squares Structural Equation Modeling (PLS-SEM). $2^{\text {nd }}$ edition. UK: Sage.

Harrigan, P., Evers, U., Miles, M., \& Daly, T. (2017). Customer engagement with tourism social media brands. Tourism Management, 59, 597-609.

Hays, S., Page, S.J., \& Buhalis, D. (2013). Social media as a destination marketing tool: its use by national tourism organisations. Current Issues in Tourism,16(3),211-239.

Henseler, J., Ringle, C.M., \& Sinkovics, R.R. (2009). The use of partial least squares path modeling in international marketing. Advances in International Marketing, 20,277-319.

Jahn, B., \& Kunz, W. (2012). How to transform consumers into fans of your brand. Journal of Sevices Management, 23,344-361.

Jin, S.-A.A., \& Bolebruch, J. (2009). Avatar-based advertising in Second Life: The role of presence and attractiveness of virtual spokespersons. Journal of Interactive Advertising, 10,51-60.

Kaplan, A.M., \& Haenlein, M. (2010). Users of the world, unite! The challenges and opportunities of Social Media. Business horizons, 53, 59-68.

Kietzmann, J.H., Hermkens, K., McCarthy, I.P., \& Silvestre, B.S. (2011). Social media? Get serious! Understanding the functional building blocks of social media. Business horizons, 54,241-251.

Kim, Y.-K. (2002). Consumer value: an application to mall and Internet shopping. International Journal of Retail \& Distribution Management, 30,595-602.

Kim, Y.-K., Kang, J., \& Kim, M. (2005). The relationships among family and social interaction, loneliness, mall shopping motivation, and mall spending of older consumers. Psychology \& Marketing, 22,995-1015.

Komppula, R., \& Gartner, W. C. (2013). Hunting as a travel experience: An auto-ethnographic study of hunting tourism in Finland and the USA. Tourism Management, 35,168-180. 
Lee, C., Hallak, R., \& Sardeshmukh, S.R. (2016). Innovation, entrepreneurship, and restaurant performance: A higher-order structural model. Tourism Management, 53,215-228.

Leung, X.Y., Bai, B.; \& Stahura, K.A. (2015). The marketing effectiveness of social media in the hotel industry a comparison of Facebook and Twitter. Journal of Hospitality \& Tourism Research, 39, 147-169.

Liang, H., Saraf, N., Hu, Q., \& Xue, Y. (2007). Assimilation of Enterprise Systems: The Effect of Institutional Pressures and The Mediating Role of Top Management. Mis Quarterly, 31,59-87.

Lu, H.-P., \& Hsiao, K.-L. (2010). The influence of extro/introversion on the intention to pay for social networking sites. Information \& Management, 47,150-157.

Main, J.C., DeBruine, L.M., Little, A.C., \& Jones, B.C. (2010). Interactions among the effects of head orientation, emotional expression, and physical attractiveness on face preferences. Perception, 39,62-71.

Marín, L., \& Ruiz de Maya, S. (2013). The role of affiliation, attractiveness and personal connection in consumer-company identification. European Journal of Marketing, 47,655-673.

Moon, Y. (2003). Don't blame the computer: When self-disclosure moderates the self-serving bias. Journal of Consumer Psychology, 13,125-137.

Nambisan, S., \& Baron, R.A. (2009). Virtual customer environments: testing a model of voluntary participation in value co-creation activities. Journal of Product Innovation Management, 26,388-406.

Novak, T.P., Hoffman, D.L., \& Yung, Y.-F. (2000). Measuring the customer experience in online environments: A structural modeling approach. Marketing Science, 19,22-42.

Oh, S., \& Syn, S.Y. (2015). Motivations for sharing information and social support in social media: A comparative analysis of Facebook, Twitter, Delicious, YouTube, and Flickr. Journal of the Association for Information Science and Technology, 66(10), 2045-2060.

Organ, K., Koenig-Lewis, N., Palmer, A., \& Probert, J. (2015). Festivals as agents for behaviour change: A study of food festival engagement and subsequent food choices. Tourism Management, 48, 84-99.

Overby, J.W., \& Lee, E.-J. (2006). The effects of utilitarian and hedonic online shopping value on consumer preference and intentions. Journal of Business Research, 59,1160-1166.

Park, H., \& Kim, Y.-K. (2014). The role of social network websites in the consumer-brand relationship. Journal of Retailing and Consumer Services, 21,460-467.

Park, Y.A., \& Gretzel, U. (2007). Success factors for destination marketing web sites: A qualitative meta-analysis. Journal of travel research, 46,46-63.

Perez-Vega, R., Waite, K., \& O'Gorman, K. (2016). Social impact theory: An examination of how immediacy operates as an influence upon social media interaction in Facebook fan pages. The Marketing Review, 16(3), 299-321.

Pew Research Center (2015). Men catch up with women on overall social media use [Website]. Available on: http://www.pewresearch.org/fact-tank/2015/08/28/men-catch-up-withwomen-on-overall-social-media-use/ [Accessed: 18-02-2017].

Puzakova, M., Kwak, H., \& Rocereto, J.F. (2013). When humanizing brands goes wrong: the detrimental effect of brand anthropomorphization amid product wrongdoings. Journal of Marketing, 77,81-100.

Schlosser, A.E., White, T.B., \& Lloyd, S.M. (2006). Converting Web Site Visitors into Buyers: How Web Site Investment Increases Consumer Trusting Beliefs and Online Purchase Intentions. Journal of Marketing, 70, 133-148.

Shukla, P. (2014). The impact of organizational efforts on consumer concerns in an online context. Information \& Management, 51,113-119.

Skadberg, Y.X., \& Kimmel, J.R. (2004). Visitors' flow experience while browsing a Web site: its measurement, contributing factors and consequences. Computers in Human Behavior, 20,403-422. 
Sparks, B. (2007). Planning a wine tourism vacation? Factors that help to predict tourist behavioural intentions. Tourism Management, 28, 1180-1192.

Verma, R., Jahn, B., \& Kunz, W. (2012). How to transform consumers into fans of your brand. Journal of Service Management, 23,344-361.

Wang, L.C., Baker, J., Wagner, J.A., \& Wakefield, K. (2007). Can a retail web site be social? Journal of Marketing, 71,143-157.

Wetzels, M., Odekerken-Schroder, G., \& van Oppen, C. (2009). Using PLS path modeling for assessing hierrachical construct models: Guidelines and emprical illustration. MIS Quarterly, 33(1), 177195.

Zeithaml, V.A., Parasuraman, A., \& Malhotra, A. (2002). Service quality delivery through web sites: a critical review of extant knowledge. Journal of the Academy of Marketing Science, 30,362-375.

Zeng, B., \& Gerritsen, R. (2014). What do we know about social media in tourism? A review. Tourism Management Perspectives, 10,27-36.

Zhou, T., Li, H., \& Liu, Y. (2010). The effect of flow experience on mobile SNS users' loyalty. Industrial Management \& Data Systems, 110(6), 930-946. 